This item was submitted to Loughborough's Research Repository by the author.

Items in Figshare are protected by copyright, with all rights reserved, unless otherwise indicated.

\title{
The interaction between supportive and unsupportive manager behaviors on employee work attitudes
}

\section{PLEASE CITE THE PUBLISHED VERSION}

http://dx.doi.org/10.1108/PR-05-2015-0136

\section{PUBLISHER}

Emerald Group Publishing Limited

\section{VERSION}

AM (Accepted Manuscript)

\section{PUBLISHER STATEMENT}

This work is made available according to the conditions of the Creative Commons Attribution-NonCommercialNoDerivatives 4.0 International (CC BY-NC-ND 4.0) licence. Full details of this licence are available at: https://creativecommons.org/licenses/by-nc-nd/4.0/

\section{LICENCE}

CC BY-NC-ND 4.0

\section{REPOSITORY RECORD}

Teoh, K., lain Coyne, D. Devonish, P. Leather, and A. Zarola. 2019. "The Interaction Between Supportive and Unsupportive Manager Behaviors on Employee Work Attitudes”. figshare. https://hdl.handle.net/2134/20814. 


\section{The Interaction between Supportive and Unsupportive Manager Behaviors on}

\section{Employee Work Attitudes}

Purpose: To use Social Exchange Theory (SET) to examine a model where supportive (SMB) and unsupportive (UMB) manager behaviors interact to predict employees' engagement, job satisfaction and turnover intention.

Design/Methodology: A cross-sectional online survey collected data from $252 \mathrm{UK}$ based employees of a global data management company.

Findings: Factor analysis confirmed manager behaviors to consist of two constructs: supportive and unsupportive behaviors. Structural equation modelling indicated SMB predicted job satisfaction and turnover intentions, but not engagement. Job satisfaction, but not engagement, mediated the SMB-turnover intention relationship. UMB only predicted job dissatisfaction. Neither job satisfaction nor engagement mediated the UMB-turnover intention relationship. UMB undermined the positive relationship between SMB and turnover intention.

Implications: The behaviors assessed can be integrated into various stages of a manager's development process to serve as guidelines of good practice. Crucially, findings suggest managers can exhibit both supportive and unsupportive behaviors, and that consistency in behaviors is important. The study also provides evidence that supportive managers can help reduce turnover intention through job satisfaction.

Originality/value: SET was used as a framework for SMB, UMB and engagement. To our knowledge this is the first study to examine the interaction between SMB and UMB.

Keywords: Supportive manager behaviors; unsupportive manager behaviors; social exchange theory; job satisfaction; engagement; turnover intention

Article Classification: Research paper 


\section{The Interaction between Supportive and Unsupportive Manager Behaviors on}

\section{Employee Work Attitudes}

The quote "People leave managers, not organizations" (Tate and White, 2005, p.2) is often cited when discussing turnover. As social support is an important source in reducing the risks of workplace stressors and in protecting worker health, a manager who is seen as supportive is more likely to have employees who intend to remain in their current employment (Maertz et al., 2007). The evidence has demonstrated consistently that positive social support is associated with improved engagement (MacLeod and Clarke, 2009), organizational citizenship behavior (Chênevert et al., 2015), wellbeing (Luchman and Gonzalez-Morales, 2013), job satisfaction and productivity (Baruch-Feldman et al., 2002). Hence, in trying to improve the working environment, social support is a crucial buffer towards workplace stressors, and it is important to understand what impact support from the manager has on the employee.

Although supportive manager behaviors (SMB; Rooney and Gottlieb, 2007; Yarker et al., 2007) and perceived supervisor support (Shanock and Eisenberger, 2006) have received considerable attention, the effects of unsupportive manager behaviors are less commonly examined (UMB). What is known typically stems from the more extreme side of negative leadership, such as abusive supervision (Mitchell and Ambrose, 2007) and destructive leadership (Schyns and Schilling, 2013). Even less attention has been given to the idea that managers can exhibit different types of leadership behaviors (Kelloway et al., 2006), and little is known about the possible interactions between SMB and UMB. Consequently, this study examines the construct of SMB and UMB using Social Exchange Theory (SET) in relation to three common employee measures: engagement, job satisfaction and turnover intention (See Figure 1 for proposed model). The selection of engagement reflects the interest of the UK government in the manager-engagement relationship (MacLeod and Clarke, 2009). 
In addition, another popular SET employee attitude (job satisfaction) is included as a comparison, and we continue the examination of other researchers (Rooney et al., 2007; 2009) on the impact of SMB on turnover intention.

\section{[Insert Figure 1]}

Social Exchange Theory in the Workplace

Social Exchange Theory (SET; Blau, 1964) is among the most influential frameworks in understanding organizational behaviors (Cropanzano and Mitchell, 2005), and states that relationships are maintained between two parties by a state of reciprocal interdependence. It proposes that when one party acts in a manner which benefits a second party, there is an obligation and expectation that the second reciprocates the favor (Blau, 1964). Unlike economic or contractual exchanges, SET is predicated by relationships which are nurtured over time (Aryee et al., 2002), with reciprocation of the socioemotional benefits having behavioral, cognitive or emotional implications (Blau, 1964; Cropanzano and Mitchell, 2005). This means that trust is an important tenant in such a relationship as when, and in what form, the favor should be returned is unclear. It can be construed that the employee and the source of support are two actors in the exchange relationship. Within organizational research, SET typically examines how perceived organizational and supervisor support is reciprocated by employees, with a growing evidence base highlighting the positive influence organizational and supervisor support has on job satisfaction, organizational citizenship behavior and performance (Chênevert et al., 2015; Kang et al., 2011; Shanock and Eisenberger, 2006).

In addition to the source, a second aspect of support is the type of support, which comes in the form of instrumental and emotional support (Haslam et al., 2005). The former refers to the tangible support an employee receives to complete work duties, whilst the latter 
is the care and concern employees might receive that gives them a sense of worth and belonging. Managers have the ability to influence the work environment by providing job resources and determining work conditions, thereby providing both emotional and instrumental support in the workplace (Luchman and Gonzalez-Morales, 2013). Hence, employees are more likely to reciprocate positively to a conducive environment set by the manager (Settoon et al., 1996), explaining why the manager-employee relationship has been found to have a stronger influence on organizational outcomes than relationships with coworkers (Liaw et al., 2010). This reciprocity is typically initiated by the leader (Graen and Uhl-Bein, 1995), and if the employee responds favorably an interdependent relationship can ensue. These employees will then receive additional support, resources and opportunities (Cropanzano and Mitchell, 2005), leading to the nature of the social exchange relationship continually altering (Erdogan and Liden, 2002).

\section{Engagement}

SET provides a theoretical framework explaining employee engagement (Agarwal, 2014; Ghosh et al., 2014), which is conceptualized by Schaufeli et al., (2006) as being fully engrossed, deriving enthusiasm and pride, and having high levels of energy and investment in one's work. In a report to the UK government, engagement was identified as having a crucial role in bringing the national economy out of recession (MacLeod and Clarke, 2009; Rayton et al., 2012). So long as both parties abide by the rules of exchange, the social exchange relationships will over time, develop into loyal, trusting and mutual commitments (Cropanzano and Mitchell, 2005). This is congruent with Robinson et al.'s (2004) notion of engagement as a two-way relationship between the organization and the employee. In response to the resources received from the other party (i.e., organization, manager), employees can devote greater cognitive, emotional and physical resources to their 
organizations, and adjust the levels with which they engage their work in response to the resources and support received (Saks, 2006). To our knowledge there have been few attempts to examine engagement from a SET perspective (Agarwal, 2014: Ghosh et al., 2014), with the effect of manager support being less conclusive than that from the organization. However, while engagement is typically examined from a job demands-resources model, the positive relationship between job resources and engagement has been explained through the reciprocal nature of SET (e.g., Dollard and Bakker, 2010; Xanthopoulou et al., 2009).

The importance of managers is highlighted by the report to the UK government identifying effective managers as being one of the four drivers for engaging the workforce (MacLeod and Clarke, 2009; Rayton et al., 2012), despite the empirical evidence between manager behaviors or leadership with employee engagement being less clear. Rhoades and Eisenberger's (2002) meta-analysis on organizational support theory, which includes supervisor support as a representative of the organization, did not include engagement. In a review of 91 studies, Christian et al. (2011) found that job characteristics, leadership and employees' personality preceded engagement, with leadership having the weakest relationship with engagement. Considering that Christian et al.'s coverage of leadership only encompassed transformational leadership and the leader-member exchange, which are conceptually different from the assessment of supportive behaviors, a behavior based examination might yield different results. This study continues the work on Saks' (2006) framing of engagement within SET, that when managers meet the professional and personal needs of their employees, it is plausible that like perceived organizational support, employees reciprocate with higher engagement levels. As such, it is hypothesized that:

H1: Supportive manager behaviors are positively related with engagement.

\section{Job Satisfaction}


The inclusion of job satisfaction in this study allows a comparison with what some have argued to be conceptually similar to engagement (Macey and Schneider, 2008). According to SET, when the employee feels supported, their job satisfaction can improve as socioeomotional needs are met or there is the signaling of the availability of aid to employees (Rhoades and Eisenberger, 2002). Managers can increase the job satisfaction of their staff by providing constructive feedback that allow employees to feel valued, or by enhancing work characteristics like autonomy and group cohesion while reducing ambiguity (Lee and Cummings, 2008). Furthermore, SET postulates that perception of support can lead to employees responding affectively, with a lack of support leading to increased job dissatisfaction (Johnson and O’Leary-Kelly, 2003; Rooney et al., 2007; 2009).

Although the literature surrounding job satisfaction and manager support has focused on perceptions of support, it would be anticipated according to SET that the provision of tangible supportive behaviors will demonstrate a similar effect. As a result, it is predicted that:

H2: Supportive manager behaviors are positively related with job satisfaction.

\section{Turnover Intention}

SET would advocate that low support quality could be reciprocated by increased turnover intention (Cropanzano and Mitchell, 2005; Mossholder et al., 2005). Commitment to an organization and job can manifest itself as both an affect and/or behavior, and can therefore be used by an employee to reward or punish their managers. SMB (Rooney et al., 2007; 2009), leader-member exchange (Kang et al., 2011) and perceived supervisor support (Maertz et al., 2007; Newman et al., 2011) have used SET to explain the support-turnover intention relationship. 
Crede et al. (2007) proposed a model whereby job withdrawal cognitions, along with organizational citizenship behaviors and counterproductive workplace behaviors, were identified as groups of 'behaviors' which employees can use to reciprocate within the exchange relationship. Moreover, they argued work attitudes (namely job satisfaction) have a role in mediating the work environment and behavior relationship. Meta-analytical results (e.g., Murrells et al., 2008) illustrate that job satisfaction is inversely correlated with turnover intention. When the situation at work becomes unsatisfactory, one of the coping mechanisms would be to escape that situation (Moynihan et al., 2003) - manifesting in increased turnover intention. Extending Crede et al.'s (2007) model to include engagement as a mediator, engaged employees identify with their work and invest energy in it, and might find difficulty detaching from or even leaving their work (Halbesleben and Wheeler, 2008). By leaving the organization they lose the ability to carry on their work, and lose access to resources which has helped them with their work. This is seen in Halbesleben (2010) and Saks' (2006) studies that support a negative relationship between dimensions of engagement and turnover intention.

Despite the literature so far providing separate evidence that SMB impacts engagement and job satisfaction, and that these subsequently influence turnover intention, there have been few models that examine these together. The studies which have are consistent in their findings. Agarwal et al. (2012) found that engagement mediated the link between the quality of the employee-manager relationship and turnover intention, whilst three separate studies revealed job satisfaction to mediate social support from supervisor (van der Heijden et al., 2010) and leader-member exchange (Han and Jekel, 2011; Wang and Yi, 2011) relationship with turnover intentions. Considering the evidence supporting SMB being reciprocated with work attitudes, and extending these assumptions into a mediation model, it is hypothesized that: 
H3: Supportive manager behaviors, engagement and job satisfaction have a negative relationship with turnover intention.

H4: Engagement and job satisfaction mediate the relationship between supportive manager behaviors and turnover intention.

\section{Unsupportive Manager Behaviors}

The negative reciprocal relationship has received little attention within the SET literature, and it is less clear what the effect unsupportive manager behavior (UMB) has on the outcome measures described above. The dominance of the research literature examining supportive managers as opposed to unsupportive or abusive managers has created a myopic understanding of managers' influence on employees. The studies that have focused on negative leadership have looked at abusive, deviant or tyrannical supervision (Mitchell and Ambrose, 2007), with less attention on the more subtle forms of poor support. Aspects of work which violate SET would impair the development of a high quality relationship between the employee and manager (Cropanzano et al., 2003), infringing the implicitly understood obligations which form the psychological contract between both parties (Rousseau, 1995). This lack of support could result in employees' engaging in negative behaviors in order to strike back at the manager and/or organization (Cropanzano and Mitchell, 2005; Mitchell and Ambrose, 2007). Saks' model of engagement postulates that anything which threatens the social exchange relationship should result in disengagement. That is, issues with trust, lack of reciprocity, or psychological contract breaches may result in a weakening of this relationship, resulting in at least a reduction of engagement, if not actual disengagement (e.g., Agarwal et al., 2012). Some researchers (Uhl-Bien and Carsten, 2007) have argued that the power imbalance between the manager and the employee can result in employees being unable to reciprocate negatively due to fears about retaliation from their 
managers. Instead, this is displaced towards other parties within the work environment (e.g., colleagues, customers, organization). It is equally plausible that employees exposed to UMB simply withdraw from the relationship, breaking any link between support and outcome. This fits with Bhogaita's (2012) findings that UMB did not predict job satisfaction, engagement, job performance or organizational commitment.

Research in this area has shown SMB and UMB to be different constructs with different outcomes on employee work attitudes (Bhogaita, 2012; Rooney et al., 2007; 2009) rather than two separate ends of the same continuum. In addition to the positive influence of SMB reviewed earlier, the evidence indicates that UMB and poor leader-member exchanges are reciprocated with lower job satisfaction, organizational citizenship behavior and job performance, and increased turnover intention (Cropanzano et al., 2003; Rooney and Gottlieb, 2007; Setton et al., 1996). Employees were also found to respond to abusive supervisors with feelings of increased stress and helplessness instead of deviant behaviors, suggesting that they internalize their response and exhibit behavior that benefits them (Organ, 1990). Considering that reciprocity forms the basic tenant of SET, and the previous research findings involving work-related attitudes in this area, it is hypothesized that:

H5: Unsupportive manager behaviors are negatively related with job satisfaction, and engagement.

H6: Unsupportive manager behaviors are positively related with turnover intention.

H7: Engagement and job satisfaction mediate the relationship between unsupportive manager behaviors and turnover intention.

\section{Consistency of support}

Even with the growing emphasis of UMB (Bhogaita, 2012; Rooney and Gottlieb, 2007) and destructive leadership (Schyns and Schilling, 2013) on employee work attitudes, these have 
been examined in isolation to the positive dimension of support. How supportive a person is at work is not necessarily constant, with findings that managers (Rooney and Gottlieb, 2007), nurses (Krishnasamy, 1996) and spouses of cancer patients (Manne and Schnoll, 2001) can exhibit both supportive and unsupportive behaviors. In the safety leadership literature, Kelloway et al. (2006) argued that frequency-based measures of transformational and passive leadership styles means leaders could alternate between, or exhibit, both styles of leadership. Building on this, passive-safety leadership has been found to attenuate the positive impact that transformational-safety leadership has on safety behaviors (Mullen et al., 2011). However, aside from the work by Kelloway et al. (2006) and Mullen et al. (2011), we are unaware of any other attempts to examine the interactive relationship between leadership styles or manager behaviors.

A manager displaying frequent SMB and infrequent UMB can be said to be providing consistent support to their employees. This consistency reinforces the beneficial behavior extended to the employee, increasing the trust between both parties and creating the reciprocal obligation for the employee to respond favorably (Colvin et al., 2002; Cropanzano and Mitchell, 2005). In contrast, inconsistent support occurs when there is a mismatch between the frequency of SMB and UMB. Extrapolating from Mullen et al.'s (2011) study, any positive effect from SMB on employees would be undermined by the presence of frequent UMB. This clash hinders the development of an exchange relationship between manager and employee as the incongruent behavior on the part of the manager potentially violates one of the fundamental principles of SET - trust (Blau, 1964). Finally, managers displaying infrequent SMB and frequent UMB can be grouped as consistently unsupportive. As discussed earlier in this paper, this would have a detrimental impact on any relationship and could result in employees reciprocating with negative work attitudes or withdrawing 
from the exchange relationship altogether (Cropanzano et al., 2003; Cropanzano and Mitchell, 2005; Mitchell and Ambrose, 2007).

It is highly plausible that managers exhibit both supportive and unsupportive behaviors. As such, this current study seeks to contribute to the recent developments that examine the interactive role of SMB and UMB on employee outcomes and hypothesizes that:

H8: Employees who experience consistent support (high SMB, low UMB) will report higher levels of engagement, job satisfaction, and lower turnover intention than those who experience inconsistent support (high SMB, high UMB or low SMB, low UMB) and consistent unsupportive (low SMB, high UMB).

\section{Method}

\section{Sample and Procedure}

Participants were recruited from the UK operations of a global data management and analysis company. Four members of every team that had a manager undergoing an internal management training program were randomly selected to participate. Although the company is set within a specific industry, teams were spread across the United Kingdom and undertook a range of business functions. A total of 1,483 employees were emailed and invited to take part via an electronic survey. Information and contact details were provided on the first page of the online survey. Participants were also informed that by proceeding with the online survey they were consenting to take part. However, they were free to exit the browser and withdraw from the study. The survey window lasted three weeks, with a reminder email sent out after one week.

Overall, 288 employees completed the online questionnaire, although 36 were removed due to incomplete responses. Managers comprised $29.4 \%$ of the sample, and $54 \%$ of the sample was male. The average age was 35.4 years $(\mathrm{SD}=9.3)$, and average tenure was 6.17 
years $(\mathrm{SD}=6.59)$. Participants operated in a wide range of job functions, including Information Technology (18.3\%), Customer Services (11.5\%), Analytics (10.7\%), Finance (9.1\%), Sales (8.7\%), and Product Development (7.5\%). The remaining 34\% were employed in other business areas.

\section{Measures}

Supportive Manager Behaviors. The Inventory of Supportive and Unsupportive Manager Behavior is a 14-item measure which contains 9 supportive and 5 unsupportive manager behaviors (Zarola, 2011). Participants rate their own immediate manager in terms of how frequently they displayed these behaviors using a 5 -point frequency scale where ' $1=$ never' and '5=always'. An example behavior includes 'I have to deal with unrealistic expectations from my manager'. Past researchers (Bhogaita, 2012; Zarola, 2011) have found coefficient alphas of between .90 and .96 for SMB items and alphas of .75 to .86 for UMB items.

Work Engagement. This study examines the overall measure of engagement, and therefore, like other researchers (e.g., Agarwal, 2014), summed the subscale scores of the Utrecht Work Engagement Scale (Schaufeli and Bakker, 2003) to represent engagement. Comprising nine items, participants rated items such as 'My job inspires me' on a seven point scale with ' $0=$ never' and ' $6=$ everyday'. Internal consistency has previously been reported at .91 (Schaufeli and Bakker, 2003).

Job Satisfaction. Job satisfaction was assessed using the five items of global job satisfaction from the Andrew and Withey Job Satisfaction Questionnaire (Rentsch and Steel, 1992). The measure included items such as 'How do you feel about your job?' which was rated on a seven point scale where ' $1=$ terrible' and ' $7=$ delighted'. 
Intention to leave. Rosin and Korabik's (1991) four item scale was used. Three items were weighted with three answer options (e.g., are you planning to leave your job within the next six months?; 'yes=2', 'no=0', and 'unsure=1'). The fourth item ('are you actively searching for another job right now?'), was weighted 'yes $=2$ ' and 'no=0'. These were summed, with a higher score indicating stronger intention to leave. Foley et al. (2002) found inter-item reliability to be at .83 .

Control variables. Although demographic characteristics have little effect on relationships within the support and SET literature (Shanock and Eisenberger, 2006), in line with common practice, age, gender, job tenure, and manager/employee status were included as control variables in the structural equation and the moderated regression models.

\section{Results}

Due to questions arising surrounding the conceptualization of supportive (SMB) and unsupportive (UMB) manager behaviors as either one (Yarker et al., 2007) or two separate constructs, a confirmatory factor analysis (CFA) was conducted to confirm that SMB and UMB composed a better two-factor model than a singular factor model (Rooney et al., 2007; 2009). Analysis showed a two-factor model $(\mathrm{CFA}=0.95, \mathrm{RMSEA}=.08)$ was a better fit than a one-factor model $(\mathrm{CFA}=0.90, \mathrm{RMSEA}=0.11)$.

Internal reliabilities, means and standard deviations for all variables are displayed in Table 1 along with correlational coefficients. SMB was positively correlated with engagement $(r=.45)$ and job satisfaction $(r=.54)$ while negatively correlated with turnover intention $(r=-.50)$. The opposite relationships were observed for UMB, which was negatively related to engagement $(r=-.32)$ and job satisfaction $(r=-.49)$ and positively related to turnover 
intention $(r=.39)$. Turnover intention showed negative relationships with engagement $(r=-.61)$ and job satisfaction $(r=-.65)$. These support all the correlational hypotheses (H1-H3 and H5H6) made.

\section{[Insert Table 1]}

Latent SEM analyses were used to examine job satisfaction and engagement as mediators of SMB and UMB on turnover intention. Based on recommendations by Little et al. (2002) on item parceling in SEM, an empirically-guided approach to parcel construction via exploratory factor analyses was used to generate empirically robust parcels for SMB, $\mathrm{UMB}$, engagement, job satisfaction and turnover intentions. All latent variables (i.e., SMB, UMB, engagement, job satisfaction, and turnover intention) had at least two parceled indicators and exhibited high internal reliabilities (alphas $>$.70). Little et al. (2002) argued that latent models with parceled indicators (compared to item-level indicators) provide more rigorous and unbiased model estimates in SEM Model fit statistics. Consistent with Anderson and Gerbing's (1988) two-step approach, two models were specified and estimated: a measurement model including all possible correlations among latent variables and a structural model testing the main study hypotheses including the claim that job satisfaction and engagement act as mediators in the relationship between SMB/UMB and turnover intentions. Control variables of age, gender, job tenure, and manager/employee status were included in the analyses. All exogenous variables including these controls were allowed to covary, and the two mediators of job satisfaction and engagement were also allowed to covary. In order to control for common method bias, a single latent factor was included in both measurement and structural models, with direct paths to all observed variables (indicators) that were measured in the same survey. The models were run with and without this latent method factor to assess differences in parameter coefficients, which were deemed marginal. 
Confirmatory factor analyses were conducted to assess the overall measurement model. These results indicated good model fit of the measurement model, $\chi^{2}(44)=88.0$, $\mathrm{p}<.001 ; \mathrm{RMSEA}=.06$ [C.I $.04-.08], \mathrm{CFI}=.98, \mathrm{NFI}=.97, \mathrm{IFI}=.98 . \quad$ Following this model, the structural model was estimated (see Table 2). This model also reported equally good model fit, $\chi^{2}(46)=90.7, \mathrm{p}<.001$; RMSEA $=.06$ [C.I .04 -.09], CFI=.98, NFI=.97, IFI=.98. Based on an inspection of individual path coefficients, SMB had significant positive effects on job satisfaction $(b=.53, p<.001)$ and engagement $(b=.95, p<.001)$. Job satisfaction, in turn, had a significant negative effect on turnover intentions $(b=-.38, p<.001)$. However, engagement did not generate a significant effect on turnover intention $(b=-.07, p>.05)$. The bootstrapping model results revealed that the standardized mediated or indirect effect of SMB on turnover intention via job satisfaction and engagement was statistically significant (standardized estimate $=-.36, p<.05,95 \%$ C.I: $-.51--.21)$. Specific tests of indirect effects of each mediator revealed that although job satisfaction fully mediated the relationship between SMB and turnover intention $(\mathrm{z}=-3.42, \mathrm{p}<.001)$, engagement failed to mediate this relationship $(\mathrm{z}=-1.60$, $\mathrm{p}>.05)$.

UMB had a significant negative effect on job satisfaction $(b=-.31, p<.05)$ but its effect on engagement was not significant $(b=.16, p>.05)$. The total standardized indirect effect of $\mathrm{UMB}$ on turnover intentions was not statistically significant $(b=.13, \mathrm{p}>.05,95 \%$ C.I:-..03 to .28). Specific indirect effect tests revealed that neither job satisfaction $(z=1.95, p>.05)$ nor engagement $(\mathrm{z}=.72, \mathrm{p}>.05)$ mediated the relationship between UMB and turnover intentions. In light of the SEM results, H4 was partially supported as only job satisfaction, and not engagement, mediated the relationship between SMB and turnover intention. However, as neither job satisfaction nor engagement mediated the UMB and turnover relationship, H6 was rejected. 


\section{[Insert Table 2]}

Moderated regressions were conducted to examine the interactive effect between $\mathrm{SMB}$ and $\mathrm{UMB}$ on engagement, job satisfaction and turnover intention. Interactive terms (SMB x UMB; Block 3) were added to a regression model after control variables (Block 1) and main effect terms (Block 2). All items were centered before being entered into the regression. The results, presented in Table 3, show that none of the control variables predicted outcomes, with the exception of manager/employee status on engagement. In terms of the interactions, the SMB $x$ UMB interaction was only significant for job satisfaction $(b=-$ $.37, \mathrm{p}>.05$ ). When the interaction for job satisfaction was plotted (Figure 2), as expected consistent support (high SMB, low UMB) reported higher job satisfaction than inconsistent support (high SMB, high UMB or low SMB, low UMB) and consistent unsupportive (low $\mathrm{UMB}$, high SMB). However, H8 is only partially supported as no interactive effects were found for engagement or turnover intentions.

\section{[Insert Table 3]}

\section{[Insert Figure 2]}

\section{Discussion}

In answering the call for more empirical work to be done on supportive manager behaviors (Yarker et al., 2008), the current study provides a number of important contributions. Firstly, the confirmatory factor analysis strengthens the notion that SMB and UMB are two separate constructs, not two ends of the same continuum. Moreover, that different behaviors predict different outcomes provides further evidence that UMB is a different construct. What this means is that a high score on a particular construct represents more frequent demonstration of 
such (un)supportive behaviors, with a low score representing less frequent, or absence, of said behaviors. For example, a low frequency score on any item does not suggest this behavior is not encouraged, but rather that this behavior does not exist. This is more aligned with the findings of Rooney et al. $(2007 ; 2009)$ than with those proposed Yarker et al. (2008), and is akin to the examination of behaviors in other aspects of organizational research (i.e., counterproductive versus citizenship behavior; Coyne et al., 2013). As both types of supportive behaviors are distinct, it is therefore possible for managers to display both supportive and unsupportive behaviors towards their employees.

Secondly, the findings provide empirical support for the theoretical concept of SET advocating a positive relationship between SMB and the employee measures of job satisfaction, engagement and turnover intention. SET postulates that the provision of what the employee desires (more support) would be reciprocated through improved affect (i.e., job satisfaction and engagement), or by becoming more committed to their work and organizations, and the results here correspond with that of past research (Coomber and Barriball, 2007). Alternatively, as causality cannot be established, it is possible that stronger affect and commitment might be reciprocated with more supportive behaviors by managers. This also explains the finding that managers were more engaged than non-managers, as managers reciprocate their promotion by becoming more engaged in their work (Saks, 2006). However, this observation does not apply to job satisfaction and turnover intention, which warrants further theoretical and empirical exploration.

As expected, job satisfaction mediated the relationship between SMB and turnover intention, although this was not the case for engagement. Supportive managers improve the work environment and make it more satisfying by providing job support, constructive feedback and encouraging personal development (Coomber and Barriball, 2007; Lee and Cummings, 2008). This increases employees' desire to stay in that environment, and reduces 
their need to escape from unpleasant situations (Moynihan et al., 2003). The mediation result helps bridge the gap between past research that shows a link between manager support and job satisfaction (Baruch-Feldman et al., 2002; van der Heijden et al., 2010), and between job satisfaction and turnover (Murrells et al., 2008).

Engagement did not mediate the relationship between SMB with turnover intention. The results indicate that while managers influence how engaged and satisfied employees are at work; this does not translate to reduced turnover intention. The lack of a mediation effect by engagement can be attributed to the absence of the engagement-turnover intention relationship, in contrast to previous findings (Halbesleben, 2010; Saks, 2010). However, Halbesleben and Wheeler (2008) observed that engagement did not predict turnover intention, and attributed it to unique sample characteristics, or the attrition rate of their longitudinal design. Moreover, they found the strength of the correlation between engagement and turnover intention to weaken considerably when other variables were accounted for. Considering the debate on whether engagement and job satisfaction are conceptually different (Macey and Schneider, 2008), it is plausible that the global nature of job satisfaction might be more salient than engagement, thereby leaving little unique variance for engagement. In future, the unique contribution of engagement on turnover intention warrants closer examination.

SET would predict that UMB be reciprocated with negative affect (reduced job satisfaction), which was observed. The study also provides support for Kelloway et al.'s (2006) rationale that leaders can exhibit different leadership behaviors, interacting to influence employee outcomes. Our study echoes that of Mullen et al. (2011) whereby the positive influence of SMB on job satisfaction is undermined by frequent UMB. This highlights the importance of consistency in the provision of support to employees when developing a reciprocal relationship. When managers behave inconsistently employees may 
not trust the intention of the manager, in turn perceiving less of a need to respond favorably. However, UMB was not related negatively to engagement or positively with turnover intention as postulated by SET. Ultimately, the absence of these relationships means a lack of mediators between UMB and turnover intention, in contrast to what was predicted. Similarly, the proposed undermining of SMB on engagement and turnover intention by UMB was not found. SET theorizes that humans seek to maximize benefits and reduce conflict and costs within social relationships (Chibucos et al., 2005). Consequently, becoming disengaged or intending to leave when exposed to unsupportive behaviors might be deemed detrimental to an employee. Instead, they might choose to ignore these unsupportive behaviors and not allow it to impact them. On the other hand, job satisfaction is influenced by UMB because as an affect it is internalized by employees and more difficult to be picked up by managers. The absence of a UMB-turnover intention relationship could also be attributed to a difference between desire and intention. Unaccounted variables such as perceived employability and the current job market might confound this relationship, possibly leading to a lack of intention to leave even when the desire exists. However, it is worth noting that Bhogaita's (2012) finding that UMB did not predict organizational commitment suggests that this explanation might be less plausible than that proposed by SET perspective.

\section{Practical Implications}

These findings suggest that organizations trying to reduce turnover intention should ensure their employees are satisfied with their work by improving the support they receive from managers. Managers should provide clear instructions, be able to provide constructive criticism, and take interest in their employees' wellbeing and development (Lee and Cummings, 2008). Crucially, there has to be recognition that managers can exhibit both supportive and unsupportive behaviors, meaning there likely is scope for improvement 
amongst even the most supportive managers. These two forms of behaviors also have the potential to interact, and therefore managers need to be made aware that inconsistency only undermines how supportive they come across to their staff. The supportive behaviors contained in the SMB measures can be integrated into various stages of a manager's development process, including selection, training and appraisals, where it can serve as a guideline of good practice. In contrast, the UMB guidelines serve as example behaviors to avoid in the workplace.

Although not examined in this study, it is worth noting that alongside manager support, having a supportive organization is also crucial in creating an environment that encourages engagement and satisfaction (Maertz et al., 2007). While managers have a degree of control, they are often restricted by organizational factors placed upon them, such as pay and benefit packages, training and developmental opportunities (Shanock and Eisenberger, 2006). This means that managers could act as a gatekeeper towards these resources, and organizations themselves have to be supportive of their managers and provide them with the required resources needed to support employees.

\section{Limitations}

Certain limitations need to be considered when evaluating these results and when designing related studies. Firstly, future studies should consider longitudinal designs to explore possible causal effects. Secondly, the sole use of self-report measures may lead to common method bias affecting the results although self-report cannot be avoided in measuring employees' affect and intentions (Conway and Lance, 2010). It was initially planned to match employees' ratings of their managers' support with managers' self-rating to allow for matching and provide an alternate source of measurement, however low matched pairs meant this was not possible. Additional controls against common method bias include including a common 
method variance latent factor to control for it in the SEM, and by using established measures which showed validity and reliability to reduce measurement error. Also, to reduce social desirability it was emphasized that this was a study conducted external to the company and only aggregate data would be shared with the company. Third, although participants stemmed from a wide range of job functions, they were all from the same company within one UK industry sector. In addition, the low response rate means respondents might not be representative of the sample. Consequently, care needs to be taken in generalizing any findings. 


\section{References}

Agarwal, U.A., Datta, S., Blake-Beard, S. and Bhargava, S. (2012), "Linking LMX, innovative work behavior and turnover intentions: The mediating role of work engagement”, Career Development International, Vol. 17 No. 3, pp. 208-230.

Agarwal, U.A. (2014), "Linking justice, trust and innovative work behavior to work engagement", Personnel Review, Vol. 43 No. 1, pp. 41-73.

Anderson, J.C. and Gerbing, D.W. (1988), "Structural equation modeling in practice: A review and recommended two-step approach”, Psychological Bulletin, Vol. 103 No. 3, pp. 411-423.

Aryee, S., Budhwar, P.S. and Chen Z.X. (2002), "Trust as a mediator of the relationship between organizational justice and work outcomes: Test of a social exchange model", Journal of Organizational Behavior, Vol. 23 No. 3, pp. 267-285.

Baruch-Feldman, C., Brondolo, E., Ben-Dayan, D. and Schwartz, J. (2002), "Sources of social support and burnout, job satisfaction and productivity", Journal of Occupational Health Psychology, Vol. 7 No. 1, pp. 84-93.

Blau, P. (1964), Exchange and power in social life, Wiley, New York, NY.

Bhogaita, S. (2012), "Leveraging the role of the manager to improve organisational performance", paper presented at the BPS Division of Occupational Psychology Annual Conference, 9-11 January, 2013, Chester, United Kingdom.

Chênevert, D., Vandenberghe, C. and Tremblay, M. (2015), "Multiple sources of support, affective commitment, and citizenship behaviors: The moderating role of passive leadership", Personnel Review, Vol. 44 No. 1, pp. 69-90. 
Chibucos, T.R., Leite, R.W. and Weis, D.L. (2005), Readings in Family Theory, Sage Publications, London.

Christian, M.S., Garza, A.S. and Slaughter, J.E. (2011), "Work engagement: A quantitative review and test of its relations with task and contextual performance", Personal Psychology, Vol. 64 No. 1, pp. 89-136.

Conway, J.M. and Lance, C.E. (2010), "What Reviewers Should Expect from Authors Regarding Common Method Bias in Organizational Research”, Journal of Business and Psychology, Vol. 25, pp. 325-334.

Coomber, B. and Barriball, K.L. (2007), "Impact of job satisfaction components on intent to leave and turnover for hospital-based nurses: A review of the research literature", International Journal of Nursing Studies, Vol. 44 No. 2, pp. 297-314.

Colvin, M., Cullen, F.T. and Vander Ven, T. (2002), "Coercion, social support, and crime: An emerging theoretical consensus", Criminology, Vol. 40, pp. 19-42.

Coyne, I., Gentile, D., Born, M.P., Ersoy, N.C. and Vakola, M. (2013), “The relationship between productive and counterproductive work behavior across four European countries”, European Journal of Work and Organizational Psychology, Vol. 22 No. 4, pp. 377-389.

Crede, M., Chernyshenko, O.S., Stark, S., Dalal, R.S. and Bashshur, M. (2007), “Job satisfaction as mediator: An assessment of job satisfaction's position within the nomological network", Journal of Occupational and Organizational Psychology, No. 80, pp. 515-538.

Cropanzano, R. and Mitchell, M.S. (2005), "Social exchange theory: An interdisciplinary review", Journal of Management, Vol. 31 No. 6, pp. 874-900. 
Cropanzano, R., Rupp, D.E. and Byrne, Z.S. (2003), “The relationship of emotional exhaustion to work attitudes, job performance, and organizational citizenship behaviors”, Journal of Applied Psychology, Vol. 88. No. 1, pp. 160-169.

Dollard, M. and Bakker, A.B. (2010), "Psychosocial safety climate as a precursor to conducive work environments, psychological health problems, and employee engagement”, Journal of Occupational and Organizational Psychology, Vol. 83, pp. $579-599$.

Erdogan, B. and Liden, R.C. (2002), "Social exchanges in the workplace: A review of recent developments and future research directions in leader-member exchange theory", in Neider, L.L. and Schriesheim, C.A. (Eds.), Leadership, Information Age Press, Greenwich, CT, pp. 65-114.

Foley, S., Kidder, D.L. and Powell, G.N. (2002), "The perceived glass ceiling and justice perceptions: An investigation of Hispanic law associates", Journal of Management, Vol. 28 No. 4, pp. 471-496.

Ghosh, P., Rai, A., and Sinha, A. (2014), “Organizational justice and employee engagement: Exploring the linkage in public sector banks in India", Personnel Review, Vol. 43 No. 4, pp. 628-652.

Graen, G.B. and Uhl-Bien, M. (1995), "Development of Leader-Member Exchange (LMX) theory of leadership over 25 years: Applying a multi-level multi-domain perspective", Leadership Quarterly, Vol. 6, pp. 219-247.

Halbesleben, J.R.B. (2010), “A meta-analysis of work engagement: Relationships with burnout, demands, resources and consequences”, in Bakker, A. and Leiter, M.P. 
(Eds.), Work engagement: Recent developments in theory and research, Routledge, London, pp. 102-117.

Halbesleben, J.R.B. and Wheeler, A.R. (2008), “The relative roles of engagement and embeddedness in predicting job performance and intention to leave", Work and Stress, Vol. 22 No. 3, pp. 242-256.

Han, G. and Jekel, M. (2011), "The mediating role of job satisfaction between leader-member exchange and turnover intentions", Journal of Nursing Management, Vol. 19, pp. 4149.

Haslam, S.A., O'Brien, A., Jetten, J., Vormedel, K. and Penna, S. (2005), "Taking the strain: Social identity, social support and the experience of stress", British Journal of Psychology, Vol. 44, pp. 355-370.

Johnson, L.J. and O'Leary-Kelly, A.M. (2003), “The effects of psychological contract breach and organizational cynicism: Not all social exchange violations are created equal”, Journal of Organizational Behavior, Vol. 24 No. 5, pp. 627-647.

Kang, D., Stewart, J. and Kim, H. (2011), "The effects of perceived external prestige, ethical organizational climate, and leader-member exchange (LMX) quality on employees' commitments and their subsequent attitudes", Personnel Review, Vol. 40 No. 6, pp. 761-784.

Kelloway, E.K., Mullen, J.E. and Francis, L. (2006), “Injuring your leadership: How passive leadership affects employee safety", Journal of Occupational Health Psychology, Vol. 11 No. 1, pp. 76-86. 
Krishnasamy, M. (1996), "What do cancer patients identify as supportive and unsupportive behavior of nurses? A pilot study", European Journal of Cancer Care, Vol. 5 No. 2 , pp. 103-110.

Lee, H. and Cummings, G.G. (2008), "Factors influencing job satisfaction of front line nurse managers: A systematic review”, Journal of Nursing Management, Vol. 16 No. 7, pp. 768-783.

Liaw, Y.J., Chi, N.W. and Chuang, A. (2010), "Examining the mechanisms linking transformational leadership, employees customer orientation, and service performance: The mediating roles of perceived supervisor and co-worker support", Journal of Business and Psychology, Vol. 25 No. 3, pp. 477-492.

Little, T.D., Cunningham, W.A., Shahar, G. and Widaman, K.F. (2002), “To parcel or not to parcel: Exploring the question, weighing the merits", Structural Equation Modeling, Vol. 9 No. 2, pp. 151-173.

Luchman, J.N. and Gonzalez-Morales, M.G. (2013), "Demands, control, and support: A meta-analytic review of work characteristics interrelationships", Journal of Occupational Health Psychology, Vol. 18 No. 1, pp. 37-52.

Macey, W.H. and Schneider, B. (2008), “The meaning of employee engagement”, Industrial and Organizational Psychology, Vol. 1 No. 3, pp. 3-30.

MacLeod, D. and Clarke, N. (2009), “Engaging for success: Enhancing performance through employee engagement. A report to Government”, Office of Public Sector Information, Surrey. 
Manne, S. L. and Schnoll, R. (2001), “Measuring supportive and unsupportive responses during cancer treatment: A factor analytic assessment of the partner responses to cancer inventory", Journal of Behavioral Medicine, Vol. 24, pp. 297-321.

Maertz, C.P., Griffeth, R.W., Campbell, N.S. and Allen, D.G. (2007), "The effects of perceived organizational support and perceived supervisor support on employee turnover", Journal of Organizational Behaviour, Vol. 28, pp. 1059-1075.

Mitchell, M.S. and Ambrose, M.L. (2007), “Abusive supervision and workplace deviance and the moderating effects of negative reciprocity beliefs", Journal of Applied Psychology, Vol. 92, pp. 1159-1168.

Mossholder, K.W., Settoon, R.P. and Henagan, S.C. (2005), “A relational perspective on turnover: Examining structural, attitudinal, and behavioral predictors", Academy of Management Journal, Vol. 48 No. 4, pp. 607-618.

Moynihan, L.M., Boswell, W.R. and Boudreau, J.W. (2003), “The influence of job satisfaction and organizational commitment on executive withdrawal and performance”, (CAHRS Working Paper \#00-16), Cornell University, School of Industrial and Labor Relations, Centre for Advanced Human Resource Studies, Ithaca, New York.

Mullen, J.E., Kelloway, E.K. and Teed, M. (2011), "Inconsistent style of leadership as a predictor of safety behavior", Work and Stress, Vol. 25, pp. 41-54.

Murrells, T., Robinson, S. and Griffiths, P. (2008), "Is satisfaction a direct predictor of nursing turnover? Modeling the relationship between satisfaction, expressed intention and behavior in a longitudinal cohort study", Human Resources for Health, Vol. 6 No. 22, pp. 1 . 
Newman, A., Thanacoody, R. and Hui, W. (2012), "The effects of perceived organizational support, perceived supervisor support and intra-organizational network resources on turnover intentions: A study of Chinese employees in multinational enterprises", Personnel Review, Vol. 41 No. 1, pp. 56-72.

Organ, D.W. (1990), “The motivational basis of organizational citizenship behavior”, in Staw, B.M. and Cummings, L.L. (Eds.), Research in organizational behavior, JAI Press, Greenwich, CT, Vol. 12, pp. 43-72.

Rayton, B.A. and Yalabik, Z.Y. (2014), "Work engagement, psychological contract breach and job satisfaction”, The International Journal of Human Resource Management, Vol. 25 No. 17, pp. 2382-2400.

Rentsch, J.R. and Steel, R.P. (1992), "Construct and concurrent validation of the Andrews and Withey Job Satisfaction Questionnaire”, Education Psychological Measures, Vol. 52, pp. 357-367.

Rhoades, L. and Eisenberger, R. (2002), "Perceived organizational support: A review of the literature", Journal of Applied Psychology, Vol. 87, pp. 698-714.

Robinson, D., Perryman, S. and Hayday, S. (2004), "The drivers of employee engagement”, Report 408, Institute for Employment Studies, Brighton.

Rosin, H.M. and Karabik, K. (1991), "Workplace variables, affective responses and intention to leave among woman managers", Journal of Occupational Psychology, Vol. 64 No. 4, pp. 317-330.

Rooney, J.A. and Gottlieb, B.H. (2007), "Development and initial validation of a measure of supportive and unsupportive managerial behaviors", Journal of Vocational Behavior, Vol. 71, pp. 186-203. 
Rooney, J.A., Gottlieb, B.H. and Newby-Clark, I. R. (2008), “How support-related managerial behaviors influence employees: An integrated model”, Journal of Managerial Psychology, Vol. 24 No. 5, pp. 410-427.

Rousseau, D. (1995), "Psychological contract in organizations: Understanding written and unwritten agreements", Sage, Newbury Park.

Saks, A.M. (2006), “Antecedents and consequences of employee engagement”, Journal of Managerial Psychology, Vol. 21, pp. 600-619.

Schaufeli, W.B. and Bakker, A.B. (2003), "UWES-Utrecht Work Engagement Scale: Test manual”, Unpublished manuscript,. Department of Psychology, Utrecht University, Utrecht, The Netherlands.

Schaufeli, W.B., Bakker, A.B. and Salanova, M. (2006), “The measurement of work engagement with a short questionnaire: A cross-national study", Educational \& Psychological Measurement, Vol. 66 No. 4, pp. 701-716.

Schyns, B. and Schilling, J. (2012), "How bad are the effects of bad leaders? A meta-analysis of destructive leadership and its outcomes", The Leadership Quarterly, Vol. 24 No. 1, pp. 138-158.

Settoon, R.P., Bennett, N. and Liden, R.C. (1996), "Social-exchange in organizations: Perceived organizational support, leader-member exchange, and employee reciprocity", Journal of Applied Psychology, Vol. 81, pp. 219-228.

Shanock, L R. and Eisenberger, R. (2006), "When supervisors feel supported: relationships with employees' perceived supervisor support, perceived organizational support, and performance", Journal of Applied Psychology, Vol. 91 No. 3, pp. 689-695. 
Tate, R. and White, J. (2005), "People Leave Managers... Not Organizations! Action Based Leadership", iUniverse, London.

Uhl-Bien, M. and Carsten, M.K. (2007), "Being ethical when the boss is not", Organizational Dynamics, Vol. 36 No. 2, pp. 187-201.

van der Heijden, B.I.J.M., Kummerling, A., van Dam., K., van der Schoot, E., Estryn-Behar, M. and Hasselhorn, H.M. (2010), "The impact of social support upon intention to leave among female nurses in Europe: Secondary analysis of data from the NEXT survey”, International Journal of Nursing Studies, Vol. 47 No. 4, pp. 434-445.

Wang, S. and Yi, X. (2011), "Its happiness that counts: Full mediating effect of job satisfaction on the linkage from LMX to turnover intention in Chinese companies", International Journal of Leadership Studies, Vol. 6 No. 3, pp. 337-356.

Xanthopoulou, D., Bakker, A.B., Demerouti, E. and Schaufeli, W.B. (2009), "Reciprocal relationships between job resources, personal resources, and work engagement”, Journal of Vocational Behavior, Vol. 74 No. 3, pp. 235-244.

Yarker, J., Donaldson-Feilder, E., Lewis, R. and Flaxman, P.E. (2007), Management competencies for preventing and reducing stress at work: Identifying and developing the management behaviors necessary to implement the HSE Management Standards, HSE Books, London.

Yarker, J., Lewis, R. and Donaldson-Feilder, E. (2008), Management competencies for preventing and reducing stress at work: Identifying and developing the management behaviors necessary to implement the HSE Management Standards: Phase Two, HSE Books, London. 
Zarola, A. (2011), A health audit report for the Department of Health on specialist teams across the Ambulance Services within the United Kingdom, Zeal Solutions Ltd, Nottingham. 


\section{Table 1}

Means, Standard Deviations and Correlations for Whole Sample

\begin{tabular}{lcllllll}
\hline & Mean & SD & 1 & 2 & 3 & 4 & \multicolumn{1}{l}{5} \\
\hline 1. SMB & 36.04 & 7.03 & .94 & -.713 & .449 & .535 & -.499 \\
2. UMB & 6.17 & 3.82 & & .94 & -.317 & -.490 & .394 \\
3. Engagement & 46.13 & 12.45 & & & .94 & .715 & -.609 \\
4. Job Satisfaction & 25.4 & 4.57 & & & & .83 & -.648 \\
5. Turnover Intention & 3.85 & 2.65 & & & & & .74 \\
\hline
\end{tabular}

Note. $\mathrm{p}<.001$. for all correlations (1-tailed hypotheses); $\mathrm{n}=252$; Coefficient alpha reliabilities are reported along the diagonal. 
Table 2

Structural Model Paths, Estimates and Significance

\begin{tabular}{cccccccc}
\hline \multicolumn{2}{c}{ Model Paths } & Unstand. Est. & Stand. Est. & S.E & C.R & P \\
\hline W.E & $<---$ & SMB & .954 & .545 & .199 & 4.801 & $* * *$ \\
J.S & $<---$ & SMB & .530 & .434 & .133 & 3.991 & $* * *$ \\
J.S & $<---$ & UMB & -.306 & -.229 & .148 & -2.064 & .039 \\
W.E & $<---$ & UMB & .161 & .084 & .221 & .731 & .465 \\
T.I & $<---$ & J.S & -.380 & -.635 & .062 & -6.157 & $* * *$ \\
T.I & $<---$ & W.E & -.067 & -.161 & .036 & -1.871 & .061 \\
\hline
\end{tabular}

Model fit statistics: $\chi^{2}(46)=90.7, \mathrm{p}<.001 ; \mathrm{RMSEA}=.06$ [C.I $\left..04-.09\right], \mathrm{CFI}=.98, \mathrm{NFI}=.97$, $\mathrm{IFI}=.98 . \mathrm{SMB}=$ Supportive management behaviors, $\mathrm{UMB}=; \mathrm{J} . \mathrm{S}=$ Job Satisfaction; W.E. $=$ Work engagement; T.I $=$ Turnover intentions. C.R $=$ Critical ratios; S.E $=$ Standard error.

${ }^{* * *} p<.001$. Results of the final model controlling common-method bias. 


\section{Table 3}

Summary of hierarchical regression analyses with SMB x UMB interactive terms

\begin{tabular}{lllcc}
\hline Step & Predictor & Engagement & Job Satisfaction & $\begin{array}{c}\text { Turnover } \\
\text { Intention }\end{array}$ \\
\hline Step 1 & Gender & .050 & -.030 & -.079 \\
& Age & -.010 & -.106 & .118 \\
& Tenure & -.034 & .028 & -.035 \\
& Manager/employee & $-.211^{* *}$ & -.109 & .066 \\
& status & $.046^{*}$ & .022 & .019 \\
Step 2 & $\Delta R^{2}$ & $.447^{* *}$ & $.368^{* *}$ & $-.437^{* *}$ \\
& SMB & -.002 & $-.230^{* *}$ & .083 \\
& UMB & $.200^{* *}$ & $.307^{* *}$ & $.248^{* *}$ \\
Step 3 & $\Delta R^{2}$ & -.114 & $-.149^{*}$ & .006 \\
& SMB x UMB & .009 & $.015^{*}$ & .001 \\
\hline
\end{tabular}

${ }^{*} \mathrm{p}<.05 . * * \mathrm{p}<.001$ 
Figure 1

Proposed impact of support-related managerial behaviors on employee measures

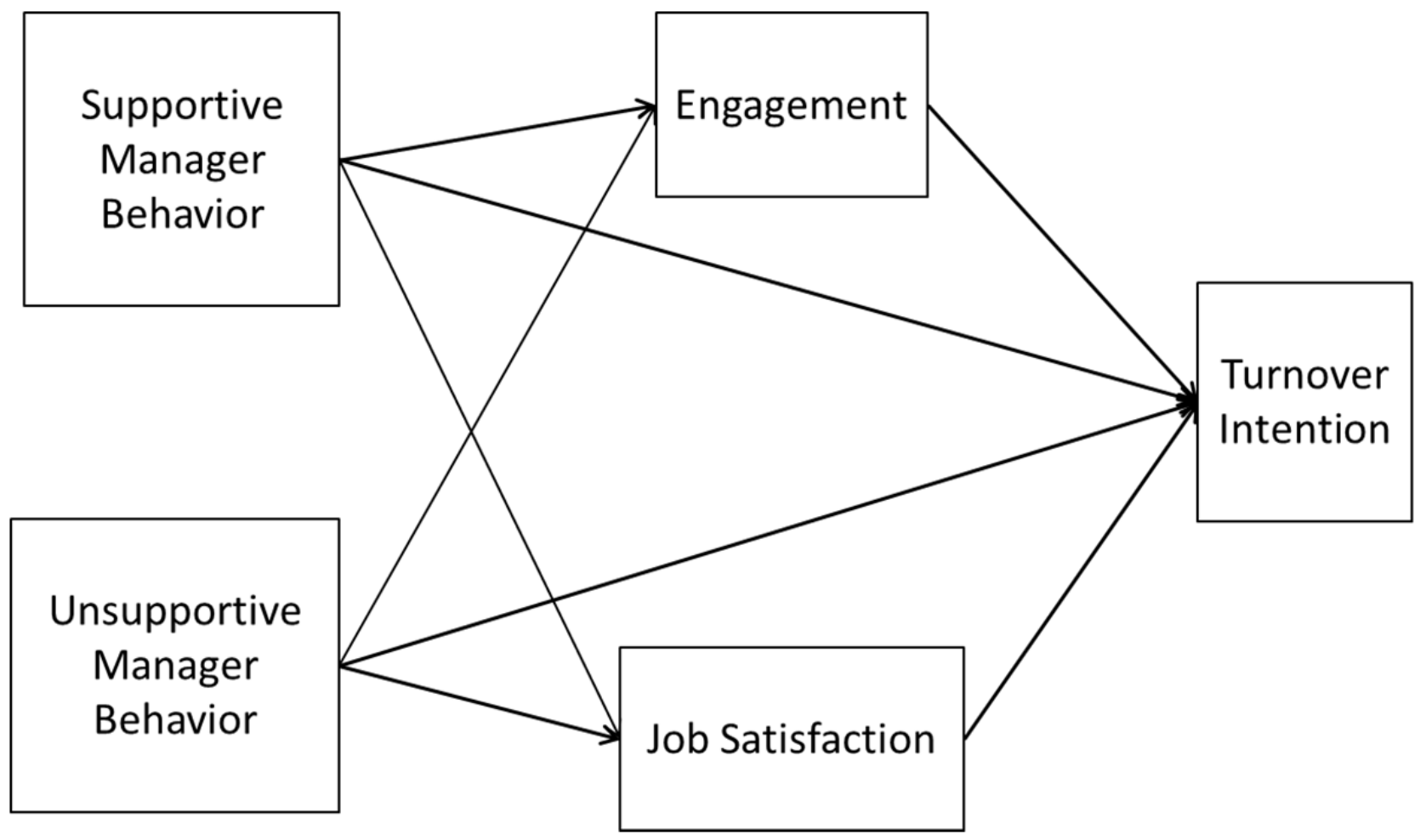


Figure 2

Interaction between SMB and UMB on job satisfaction

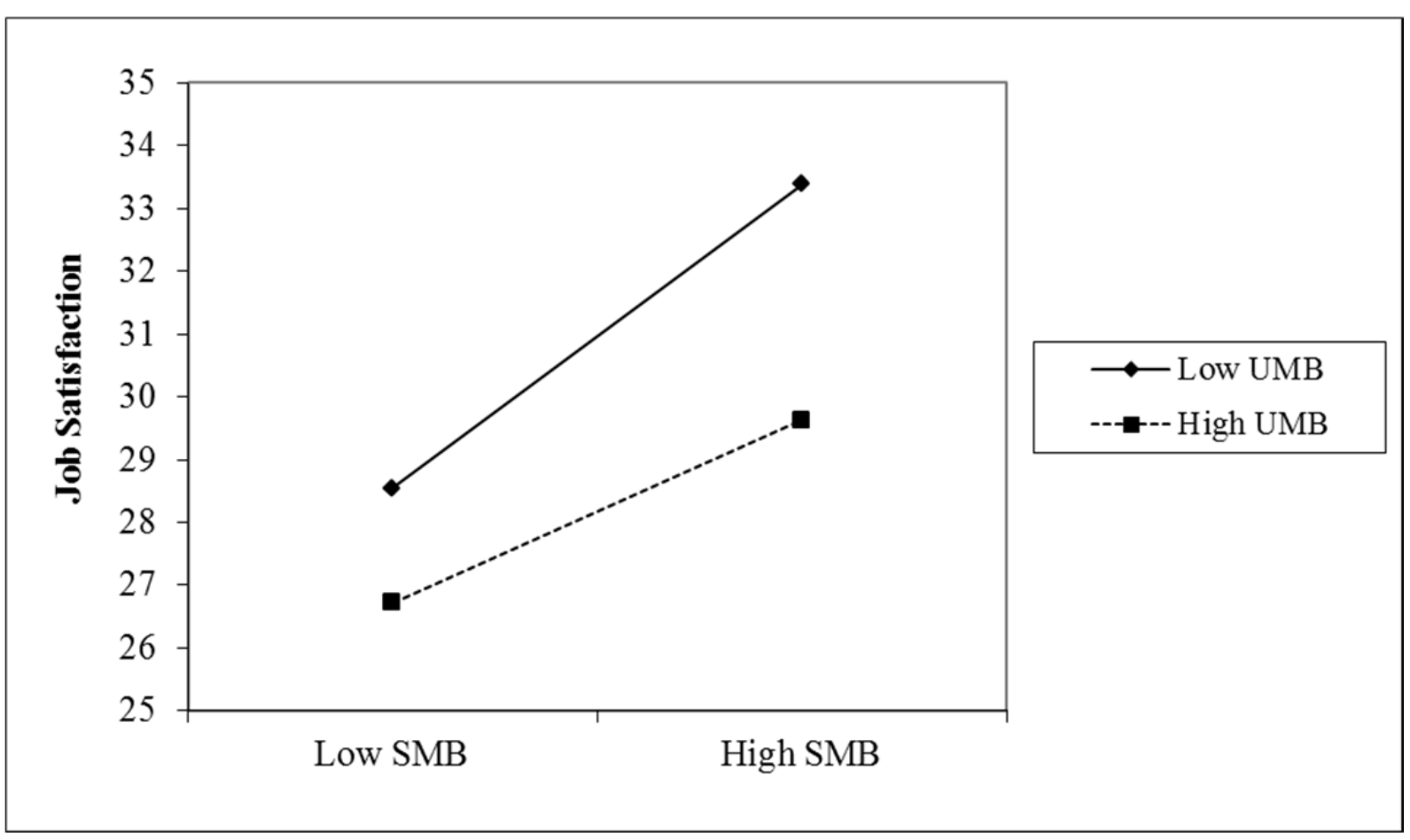

